\title{
The Research Progress on China Major Minority Detoxification Methods
}

\author{
Lei Wang ${ }^{1,2}$, Ze-Pu Yü ${ }^{1,3}$, Li-Song Liu ${ }^{3}$, Wei-Li Wang ${ }^{3}$, Han-Wen Yan ${ }^{1,3}$ and \\ Xiao-Hua Duan ${ }^{1,2, *}$
}

${ }^{1}$ The Research and Development Center for Ethno-Medicine \& Ethno-Pharmacology Yunnan university of Traditional Chinese Medicine, Yunnan University of Traditional Chinese Medicine, Kunming 650500, Yunnan Province, China

${ }^{2}$ The Key Modern Research Laboratory for Ethno-pharmacology of Yunnan Higher School at Yunnan Province; Yunnan University of Traditional Chinese Medicine, Kunming 650500, Yunnan Province, China

${ }^{3}$ The State Administration of Traditional Chinese Medicine Traditional Chinese Medicine Scientific Research Level Three Laboratory-Chinese Medicine Pharmacology Laboratory, at Yunnan Province; Yunnan University of Traditional Chinese Medicine, Kunming 650500, Yunnan Province, China

\begin{abstract}
Based on the research and material-sorting in recent decades involving Tibetan medicine Mongolia medicine Dai medicine Zhuang medicine Yao medicine, Yi medicine, Miao medicine, Jinuo medicine. Tibetan medicine has a unique system of medical theory, which posits that poisoning incidents have close relation with rLung, nKhris-pa, Badkan three factors (namely three due to), which by adjusting three due to is balance and achieve detoxification. Mongolian medicine believes that there are five-element doctrine, cold and heat, the strength and size of detoxifying respectively. "Disease first solution, the solution after the first treatment," Dai medicine "Yajie" theory and the series of Yajie (antidote)", which play a role in detoxification lies. Zhuang medicine theory includes "virtual drug-induced diseases," the etiology and pathogenesis. By correcting the bias by that bias, in order to achieve the purpose of detoxification. Yao medical theory: the Profit and Loss Balance Theory, the Cause Theory, which are related to detoxification. According to the theory of three gas, toxin factor theory as the core contents of $\mathrm{Yi}$ medical theory, which the application of detoxification method is associated with. Miao medicine thinks Poison for all ills, highlight the dispel toxin factor to the poison thery of nine. Jinuo medicine is fully application of national folk-detoxification plant and animal medicines, achieve the purposes of detoxification. In this review, we summarized the major approaches applied for detoxification methods by different ethnic groups in order to provide better guide for clinical practice of food, drugs, poisons and other toxics. This work provides also potential clinical application to open up a new way of thinking and new perspective for detoxification therapy based on the accumulated knowledge in traditional Chinese medicine.
\end{abstract}

Keyword: Traditional Chinese Medicine, Ethnic minority, detoxification drugs, ethno-medicine, detoxification methods.

\section{INTRODUCTION}

China is one of the largest multinational countries in the world with 55 ethnic minorities. Each ethic group has created something new and accumulated rich medical knowledge in its long history, which has formed colorful and various traditional ethno-medicine. Chinese traditional medicine consists of three major parts: Chinese medicine, ethnic medicine and folk medicine. Traditional Chinese Medicine (TCM), the mainstream in the ancient society, which is still worthy of the representative of Chinese traditional medical science. Unearthing the information into text has only 35 ethnic groups, of which there are 18 ethnic groups have weight ranging from medicine monographs, varying levels of clinical activity and relatively rich medicinal resources. Both of traditional medicines of

*Address correspondence to this author at the Yunnan Provincial Key Modern Research Laboratory for Ethno-pharmacology of Yunnan Higher School, Yunnan University of Traditional Chinese Medicine,Yuhua Road, Chenggong New District, Kunming, Yunnan Province 650000, China;

Tel: (+86) 871-65918160; Fax: (+86) 872-65918160;

E-mails: y.zdxh@163.com, 13526786525@163.com ethnic minorities have their own independent medical theory system, especially with detoxification-related medical theory, we need to explore the issue in depth. The ancient Chinese herbs recorded Shennong Sheng Nong's herbal classic "met the case of 70 drugs a day", which the development of medicine had experienced a witch doctor, the two solutions of the era magic pill. From a macro, holistic, heaven corresponding angle to understand human beings themselves, give maintenance, repair grant, prolong their survival time, look from nature to a lot of useful drugs, and thus create a lot of healing technology. In order to survive and the continuation of race, ancestors of China's ethnic minorities constantly had to find method of detoxification to overcome the shortage of food, and medicinal plant. In addition to find a suitable methods to eliminate poisons other toxins. Each nation have different understanding interpretation on the "Jiedu" methods in the long-term life practice. Therefore, its necessary to read through the ancient classic medical books, study how the ancients used to know, identify, 
and detoxify poisons. However, until now many of these methods were not fully explored.

\section{RESEARCH ON TIBETAN MEDICINE DETOXIFICATION METHODS}

\subsection{Tibetan Medicine Theory about Interpretation of the Relevant Toxicity and Detoxification}

Tibetan people constantly summed up medical experience in the long river of history, which was enrich and development of Tibetan medicine, Tibetan medicine was an integral part of the treasure-house of the motherland medicine [1]. Tibetan people were in the struggle with nature and disease in the lengthy process, our ancestors inevitably encountered to eat poisonous food, worm beast attacks, the occurrence of many poisoning incidents in their life. It was recorded as an alternative clinical drug upon detoxification early at ancient Chinese medicinal book "Wu Bu Yi Jiao" [2] and showed that there is "with drugs curing poison, with RangXie dealing with a record of the curse".

Tibetan medical scientists were in the summary of the national wealth of medicine based on the rich experience pharmaceutical, formed and created the theory of traditional Tibetan medicine system [3] of many pharmaceutical uses with considerable ethnic characteristics. Tibetan medicine considered that the 3factor theory of rLung, nKhris-pa, Bacon (that is, the three due), which constitute the substance of the human body, as well as the basis for essential energy and life activities [4]. Based on the above speculation as follows: When people in daily lives on a diet of toxic food, exposure to poisonous worm beast poisoning can cause Tibetan called the doctrine of the three because of changes in any of one factor or several factors, lead to be too flourish or decline the case, it becomes something pathological, eventually appears Dragon disease, Tripa disease, Bacon's disease. People can take medication to adjust to the imbalance of the three because, make those adjustment to the equilibrium state, thus avoid the happening of phenomenon of human poisoning. Etiology hypothesis [5] stated that: in terms of causes, Tibetan medicine considers that it has a common cause and special cause categories. Each of the causes have different symptoms, such as nausea, vomiting, abdominal pain and diarrhea, which are similar to the human poisoning symptoms. Tibetan people achieve balance by adjusting to the three due and taking antidotes to restore the body's normal function [6]. Ancient Tibetan physicians was in longterm medical practice, summarized up the basis of the five source doctrine theory, which was applied in the medical field of food, drugs, toxic poisoning to rescue [7].

\subsection{Overview of Tibetan Medicine Single Detoxification Drugs}

Tibetan medicine serves as an important part of traditional Chinese medicine, has a strong application foundation and long history. The Tibetan medicine theoretical system could be summarized as follow: In accordance with the potency of the drug, Tibetan medicine is divided into eight property, the six flavors, and seventeen kinds of efficiency [8]. It is the most commonly used to prevent and cure diseases, Tibetan medicine has a unique clinical efficacy, especially in toxicity accident in daily clinical activities, what seems to be more very necessary [9]. Dated back to a few centuries BC, the Tibetan people had found that the part of poisonous animals or minerals, could remove the pain, and thus realized the medical principle of "toxic that was toxic potency" [10]. The astringency of drugs such as sandalwood, Chinese tamarisk and other astringent drugs can detoxify. The classification and effectiveness of drugs were carried out according to the nature and the specific effects of the drug. Therefore, the drug were divided into: treasures drug class, stone medicine class, soil drug class, wood drug class, the essence of drug class, wet raw herbs class, xerophytic herbal class, and animal drug class [1]. Treasures drug categories representative drug as following: gold, efficacy is longevity and can answer treasure poison; Iron, can solve hepatotoxicity and other effects [11]. Red Aconitum and yellow Wutou, the effectiveness of botulinum, which the detoxify food poisoning; Pterocephalus hookeri, its efficacy is the rule of plague and detoxification; Gentiana urnula, its effectiveness of detoxification; meat categories: pig's blood, which is the efficacy of detoxification and cure convergence ulcers; manure-prepared licorice, which the effectiveness in detoxification of different types of poisons [12].

Detoxification of single flavored antidote drugs are summarized as follows: Flat Leaf Coral Disc, its efficiency is detoxification of Jie meat and aconite poisoning. Long Pinto first Pole Tubular Flowers Horse Variants is effective as antipyretic and has detoxification activities. Pulicaria is effective in the treatment of erysipelas, a variety of inflammatory and anthrax [13]. Strobilation Angle Fennel is effective in the detoxification and be used in food poisoning. The flowers of alfalfa are effectively used as antipyretic and 
detoxification [14]. Pokeweed root showed also strong detoxification activities. Drynaria baronii rhizomes are also applied as detoxifying agent and could be applied in all kinds of food poisoning such as botulism and other [15]. West Szechwan Pyrethrum is used in the treatment of a sore damp-heat, bulous pustulosis and other diseases. Lamiophlomis rotata, which is known in Tibet as "Hit Bubba" is rich source of herbal medicines with whole grass. In addition, modern research shows that Duyiwei granules have a significant role in detoxification [16]. It was also reported that the colorectal blood knot alcohol extract can inhibit blood ConA-stimulated mouse spleen cell proliferation and activation mechanism of immune suppression through reducing the expression of MAPK and NF-kappaB signal path and inhibit TNF released from macrophages with curing the expected therapeutic toxin poisoning and sepsis [17].

\section{STUDY OF MONGOLIAN MEDICINE DETOXIFICATION METHODS}

\subsection{Overview of Mongolian Medicine Theories}

Mongolian medicine is one of China's ethnic minority medicine and considered as important component of the motherland medicine [18]. Mongolian ancestors had accumulated a lot of experience in medical practice in the long struggle with disease process, and gradually developed into a unique theoretical system [19]. In the long historical process, Mongolian medicine gradually formed the five element theory and the theory of cold and heat [20]. People eat plants and animals daily, its toxic, poisoning accident inevitable occur. Thus, people were used to utilize some detoxification plant to detoxify the body and restore normal function.

\subsection{Mongolian Pharmacy Theoretical System Associated with Detoxification}

Notable features of Mongolian medicine theory system are characterized by the five element theory of Yin and Yang as a philosophy guiding ideology of the whole and its six base disorder dialectical behavioral therapy $[21,22]$. Under normal circumstances, the three root doctrine has its own characteristics; the relative balance state will maintain the unity of opposites. However, when the body suffered from eating poisoning, beast poisonous insect attacks and other pathogenic factors, three root of partial wins partial failure and reaches other abnormal state, lose balance, and thus will produce the symptoms of poisoning. This will result in the urgent needs to take Mongolian medicine detoxification to discharge toxins from the body and restore its normal function.

\subsection{Overview of Mongolian Pharmacy Related Detoxification}

\subsubsection{Mongolian Medicine Detoxifying Theory}

Mongolian medicine theories include: Five element theory, Liu wei, potency of Drug, Drug potency, Drug functions [23]. Mongolian theory under the guidance of the use of the Mongolian "Five element", "Liu wei", "Eight resistance", "the Seventeen effect" theory. In which, sweet taste can detoxify, bitterness can detoxify, with help of some plant such as Coptis chinensis. Astringent agents from some plants such as Terminalia chebula, Terminalia billericae can be used for virus eruption and sore swollen [24].

\subsubsection{Common Detoxification Drug}

Mongolian learned the essence of ethnic from Tibetan medicine theory, Han, and ancient India medicine theory and then formed their own independent medicine system [25]. The fruits of Terminalia chebulae is characterized by its salty flavor and selected by Mongolian medicine as one of the main components in detoxification to regulate body system [26]. The flowering plant Tropaeolum majus were also used in detoxification according to their medical practice [26]. Green beans can be heat and were used mainly for treatment of sore swollen poison, and food poisoning. Roots and tubers are used as antidote for the treatment of sore throat, topical treatment of snake bites with roots or the whole plant. Sanguisorba minor which is knowns as garden burnet was applied in detoxification and was applied externally for topical burn treatment. Stephania tetrandra is also other plant applied in detoxification. In addition to its topical application in the treatment of snake bite. Smilax glabra was also applied in detoxification and also in the treatment of other diseases such as leptospirosis, syphilis, carbuncle swollen boils poison, and chronic mercury poisoning [1]

\section{STUDY ON DAI NATIONALISTIC MEDICINE DETOXIFICATION METHOD}

\subsection{Theory of Dai Medicine Related with the Detoxification}

Ya Jie is an important part of Dai medicine theory, which the core theory is $\mathrm{Ya}$ Jie of the "disease first solution, after the first solution of governance" [27]. Dai people have created unique national and regional 


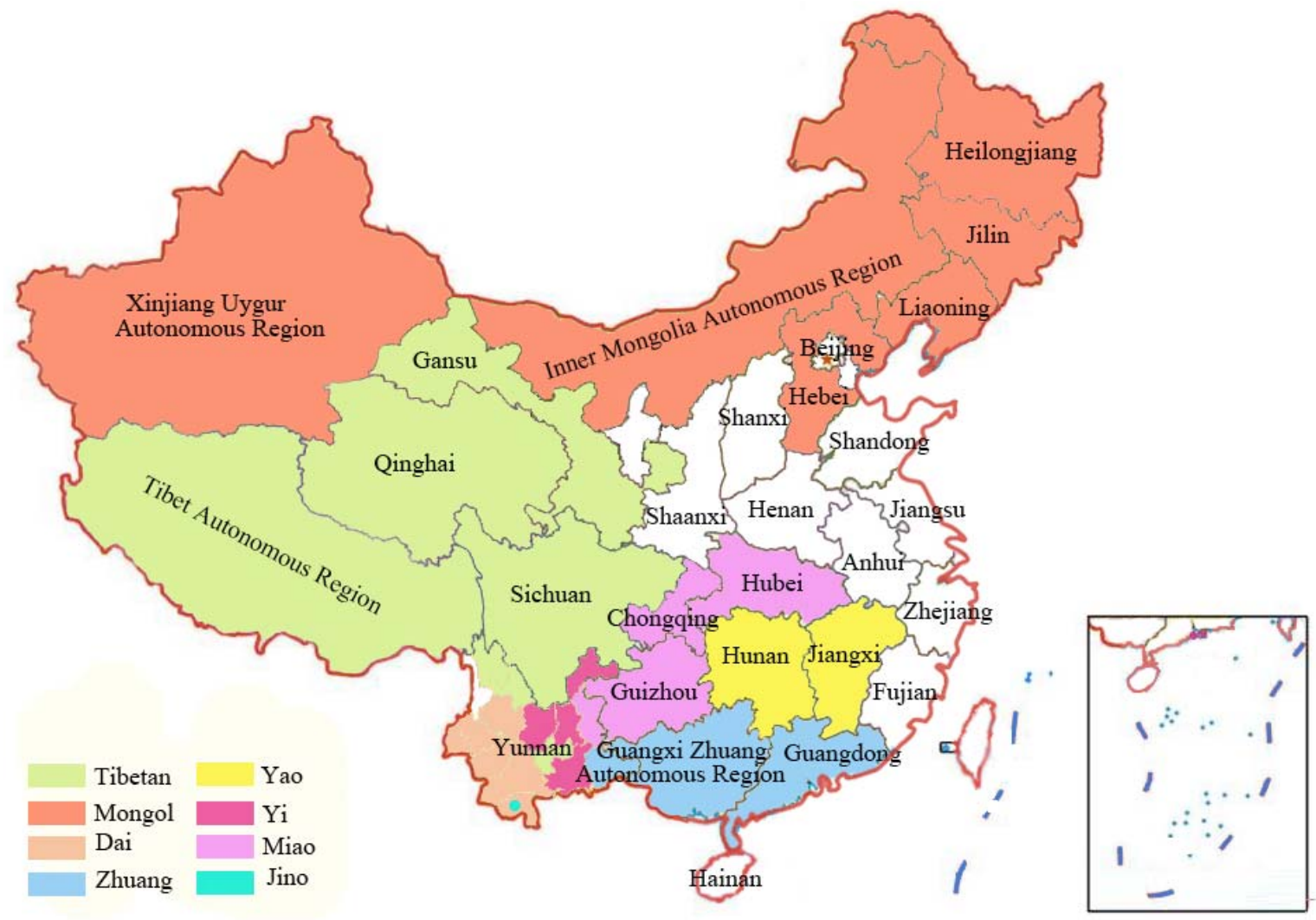

Figure 1: The geographical distribution of the eight major ethnic minorities groups in different provinces of China.

characteristics of Dai medicine basic theory in the longterm life and medical practice. Dai medicine "Ya Jie" theory and the series of "Ya Solution (antidote)" are one of the most characteristic of Dai medicine theory and prescription [28]. Dai medicine "Ya Jie" Doctrine is one of the most theoretical Dai ethnic characteristics medical theory, which is originated from the accumulated experience in the Dai people's long-term medical practice theory [29]. Dai has created many outstanding practices for detoxify drugs with traditional national and local characteristics. In recent years, Xishuangbanna district is famous with Dai folk medicine research and many useful herbal drugs of detoxification activities were developed in this region. The most famous plant applied for detoxification are include the widely grown milk fruit, elecampane, persimmon, rattan and many others [30].

\subsection{Research Overview on Ya Jie Theory (Antidote Methods)}

\subsubsection{The Concept of Ya Jie}

The Antidote in Dai called Ya Gei, which recorded as "antidote" in Literature. This can detoxify the main body from a variety of food, drugs, animal bites and other toxins with the lifting of toxins, according to Ya Jie approach [29]. People in daily life eat whole grains and cereals, take drugs, eat poisonous plants and animals. Thus, poisoning cases can hardly be avoided and excessive amount of the toxin is comes directly into the body. When the body toxin elimination mechanism dysfunction, the toxins retention in the body can cause disease. Therefore, its needed to use elegant solutions to eliminate the body of toxins and reduce the occurrence of the poisoning [31].

\subsubsection{A Summary of Ya Jie Clinical Research on the Detoxification (Antidote)}

Antidote is widely used in clinical practice, clinical indications include: remove toxic reaction caused by eating poisonous materials. It also applied after various diseases; antifebrile detoxification, relieve the body of toxic heat; snake or dog bites detoxification; hot water or fire burns detoxification; bayonet wound detoxification; bruises detoxification; drug charges, alcohol toxicity, bacteria poisoning and other factors [32]. Yubo-han points out that "elegant solution" through the decomposition, neutralization of toxins from the body in the body as a result of food poisoning, drug poisoning, and other causative agents [33].

YaJieShaBa detoxifying function of antipyretic drugs, alcohol poisoning and various other drugs, is commonly used for clinical detoxification. It is also 
applied in the treatment of symptoms caused by toxic heat flaming mouth sores and other diseased such as facial boils [34].

Dai medicine "Ya JieShaBa" plays and important role in detoxification, in addition to freeing the body from toxins, it also reduces poisoning incidence. In addition, when the body become fatigue and susceptible to disease, it is recommended to take Dai medicine as "The Elegant Solution of Sand" (Bai Jie Capsule). This also help in treatment of symptoms related to mistreatment, adverse reactions caused by improper medication [35]. Ya Jie piece is one of Dai medicine commonly used in clinical Chinese medicine as detoxifying agent in the treatment of alcohol poisoning, food poisoning, drug side effects, and variety of insects and animal poison [36].

Ya Jie detoxification is not a single compound or a single herbs. It was summarized in the "Dai Medicine Basic Theory" [37] as follows: "Ya solutions" (antidote) is divided into six categories: antipyretic drug category, for a variety of diseases in vivo toxic heat flaming, mainly including $\mathrm{Ya}$ Jie $\mathrm{Ha}$ Gan; detoxification antipyretics class, mainly including Hao Huai Teng; Jie snakes, centipedes, poisonous, Wen Shang Hai. Antialcoholism class, such as elegant solution of the first hit. Solutions of opium class, such as Fu Nan Long; Solutions poisoning bacteria, anesthesia, pendulum cumopyran poisoning.

\subsubsection{Overview of Experimental Studies on Ya Solutions (Antidote) Prescription}

The Studies of Wang xuemei on Dai medicine who did some experimental antioxidant research, showed that the extract can effectively clear oxygen free radicals, with good detoxifying effect [38]. Dai rong research of Dai medicine and other research in "YaJieShaBa " shows the impact on drunk imbalance in mice, the result showed also that antidote has obviously effect of relieving alcoholism with significant liver protection effect [39]. Other research was also carried out on Dai medicine "YaJieShaBa", the experimental results showed that elegant solutions are certain to the toxic effects of sand antidote [40]. Other YaJieShaBa" experimental study on reported on significant anti-allergic, with anti-hypersensitivity effect [41]. Other research conducted in " YaJieShaBa " showed the anti-drunk, hangover effect and the protective effect of alcohol poisoning and reduce the death rate in mice. The experimental results showed "YaJieShaBa" can significantly reduce the number of death in drunken animal model in mice, prolong the latency, drunk to shorten the duration, significantly reduced the mortality of mice with severe alcohol poisoning [42]. Gao min and his group studied Dai medicine Ya solution showed protective effect on liver injury induced by AIDS antiviral drugs, the experimental results showed that Nevirapine (NVP) can cause liver injury in mice. Application of elegant solutions from the first hit of NVP can reduce mice liver injury through some sort of protection mechanism, suggesting that it play a role in detoxification through liver protection [43]. Other research conducted by Gao yuntao and his coworkers the effect of ethyl acetate extract of purpleback murdannia on carbon tetrachloride-induced lipid peroxidation inhibition. The results show that the bamboo orchid Arundina graminifolia has some sort of detoxification mechanism on lipid peroxidation induced by chemical poisons [44].

\section{RESEARCH ON THE ZHUANG MEDICINE DETOXIFICATION METHODS}

\subsection{The Zhuang Medicine Overview}

The Zhuang Medicine is a precious cultural heritage of the Zhuang people and considered as important part of traditional Chinese medicine [45]. In the long struggle against natural disasters and diseases, it has been accumulated experiences in the prevention and treatment of diseases, gradually formed with the ethnic characteristics of Zhuang Medicine [40]. It was considered as part of the Zhuang culture system of Zhuang medicine, for a long time, with its unique national style and strong local characteristics of the spread in the folk. The long history of Zhuang medicine, the theory of rich and colorful diagnosis and treatment techniques of primitive simplicity and efficacy of medicine, has become an important part of the national Chinese traditional medicine [46].

\subsection{Overview of the Related Zhuang Nationality Medicine Detoxicating}

The development history of Zhuang medicine, roughly installments as follows:

Zhuang medicine in the pre-Qin Dynasty began to sprout: the Qin Dynasty, the drug has been recognized, and gradually accumulated in some clinical knowledge [1]. For example cook with $\mathrm{Hao} \mathrm{Su}$ ( $\mathrm{Zi} \mathrm{Su}$ ) snails mussels to detoxification of food [47].Formation and Development of Zhuang medicine: In the Tang and Song dynasties, when Lingnan people has 
accumulated rich experience in the treatment of malaria, book describes a collection of some prescriptions on the the Lingnan detoxification approaches used in the treatment of malaria [48]. Understanding of the miasma, and scroful: History books of Zhuang autonomous region and other quotidian records, such as "biography of Han Ma Yuan Zhuan." Contains: "Expedition Cochin, earth and more miasma Matrimony by malaria epidemic deceased fourteen five." Then it was observed that the Zhuang people had reached certain level of knowledge in the treatment of insanity poison, gall tumors and other illnesses [49].

\subsection{Overview on Zhuang Pharmacy Associated with Detoxification}

Zhuang medicine believe that the therapeutic effect of drug, which is that the taste of its bias to correct the Yin and Yang of human morbid under partial victory and three gas unsynchronized state to distinguish between the function of detoxification and tonic two categories [50]. In the Qin and Han dynasties Zhuang ancestors they used several species of animals and plants, minerals herbs, for the application of Zhuang medicine on the poison and antidote in in Chinese traditional nation medicine.

\subsubsection{Commonly Used Zhuang Medicine Detoxification Drug}

Zhuang autonomous region poisonous miasma of animals and plants is due to some wild flora and fauna and other toxins produced more particularly by poisonous weeds, and poisonous insects. The widespread use of poisons and antidotes is an important therapeutic features and outstanding contribution of Zhuang Medicine. Zhuang medicine believes that the reason of viral pathogenicity is first because of its toxicity which causes a fight between the virus and human body The second is that some alternative poison in the human body block air flow, so that the gas cannot be synchronized in the body and thus resulted in body weight loss, nausea, vomiting and other symptoms similar to poisoning [51].

Jin Dynasty Ge hong "ZhouHouBeiJiFang" also recorded experience by Vulgar people Lingnan sand lice for poison prevention, malaria, curare poison, and venom [47]. These records can be supported by Zhuang ancestors and used in the treatment of the toxicity of pathogenic agents [49].

From the early 1970s, Mawangdui discovered "52 sick side" and describes the treatment of common diseases using Zhuang medicine, such as snake venom, mulberry juice. From the tributes to the detoxification of Artemisia in Soviet Union, they treat the venom with mulberry juice. This to a certain extent according to the ancient Zhuang drug detoxification on the level of awareness and application [48].

Song "Gui Hai Yu Heng Chi" and "Ling Wai Dai Da " antidotes studies documented many species, such as geese hold Yizhou solutions, curare solution, mountains bean root solution, sweet banana root solution, olive poisoned puffer fish solution [48]. Hypericum has a detoxifying effect, primarily for the treatment of acne, throat and mouth disease, boil, snake bites, and others [52]. Principles for the usefulness of antidotes detoxification is applied for poisoning such as: snake poisoning, food poisoning, and poisoning caused by malaria drugs. Commonly used antidotes are: ginger, green beans, licorice, green beans and sugar. This all called "universal antidote" according to Zhuang folk [53,54]. Other research was focused also on the collection of Lingnan endemic prescription used in the medical treatment of rash, malaria based on local folk experience [55]. In general, Zhuang medicine classified antidote according to their efficacy, which is divided into antidote to poison, Snake poison antidote, food poisoning antodote, metal poison antidote, poisonous miasma antidote, and antidote for the detoxification of wide range of drugs [56].

\subsubsection{Zhuang Medicine Detoxification Theory}

Zhuang medicine theory from "poison imaginary diseases caused by" the etiology and pathogenesis, stress the detoxification. The national medical GuoYi Zhuang medicine expert professor Ban Xiuwen reported that that detoxification is mainly based on external treatment [57]. Zhuang medicine theory emphasizes on toxicity prevention by early application of antidotes.

\section{STUDY ON YAO MEDICINE DETOXIFICATION}

\subsection{Yao Medical Related Overview of Detoxification}

Yao people have accumulated rich experience in the practice process of fighting with the disease and gradually formed a set of medicine with the national characteristics based on their treatment theories. Such as a Yao Jia first treasure of spiritual herbs Lysimachia foenum-graecum Hance herbs, with its ability to treat snake bite poisoning [58]. According to the taste of the drug and clinical characteristics of the condition being treated, Yao ancestors found the traditional medicines 
summarized as "Fab Five" , "Nine cow", "eighteen drill", "72 Style" classification [59]. Yaoyi think "tiger" drug like properties of the fierce, fast effect, much as the swelling analgesic drugs; "wind" drugs for various performances, and Qingrejiedu, Qufeng Lishi, Huoxue Tiaojing drugs [60].

\subsection{Theoretical Foundation of Yao Medicine Detoxification}

Yao nationality ancients used herbal medicine to heal ulcer and some people from Chuangdu from well known for their good herbal knowledge [61]. It includes some theories such as: Profit and loss balance theory: Yaoyi think about the balance among human organs, between human organs and the external environment, Yao cure the disease through a variety of drug approaches to promote the break even among the various organs of the body, to treat a variety of poisoning and other diseases. The second is the Etiology theory, in which Yaoyi think that there is a very close relationship between human illness and the natural environment [62].

\subsection{Research of Yao Pharmacy Detoxification Drug}

Yao folk medicinal drug is basically adopts from the Dayaoshan rich herbal and animal drug and using mainly fresh spices [63]. The wide drug Rouhuan and staunch has some compatibility with drugs and can reduce drug bias adverse stimulus on the body, and reduce toxic side effects. For example, Bamboo leaves are commonly used to treat snake bites, swelling of unknown drugs and other effects [64]. Yaoyi traditional drugs are commonly summarized as "Fab Five, nine cattle, eighteen drill, seventy-two wind" in folklore medicine [65]. (1) Fab Five drugs: the mountain tiger, belonging to fight drugs, can detoxify except insanity, detoxification and other effects, attending snake bite; mountain tiger, can detoxification of swelling and, boils; Fierce tiger, attending carbuncle sore swollen poison, snake bites and other poisons [66]. (2) The nine cattle medicine: Yellow nine cattle has detoxification effect. (3) eighteen drill: red diamond, can detoxify different types of poisons except ; White Diamond, attending snake bite. (4) Section seventy-two Wind: Day Nine wind, can remove method of detoxification, in addition to the main snake bites, scabies, and swelling by unknown drugs. Flooding wind function is detoxification, attending carbuncle swollen poison, and snake bites. (5) Other Yao common antidote: plum buckle (Honey comb), they have detoxification function and act against poison attack, attending ulcer, ring worm sores, swelling bee sting. Realgar has also some activity in detoxification and attending ulcer, and also used externally in the treatment of pest and snake bites. According to the "Flora of China" record, the Yao drug small purple cow which belongs to small Myrsinaceae family, has also detoxification effect when used as whole plant [67].

\section{STUDY ON THE YI SCHOOL DETOXIFICATION MEDICINE}

\subsection{Overview of the Yi Medicine Detoxification- Related [68-69]}

Yi people accumulated a wealth of medical knowledge, and gradually formed a "three gas theory", by voicing two gasification born five elements theory, toxin theory and concept of Yin and Yang as the core content traditional Yi Medicine theoretical system [70]. The earliest record of drug detoxification was reported in the ancient $\mathrm{Yi}$ language as "poison bites musk brought deposited" [71].

\subsection{An Overview of $\mathrm{Yi}$ Medical Detoxification Associated With Basic Theory [68]}

The "Three gas theory" includes Strength, Clear air and the Aggregate. Human Spirit QI has the function of defense immunity, resists outside poison invasion, $\mathrm{Yi}$ doctors have reported on "vitality filling, body difficulties to commit toxin, toxin related diseases, vitality first virtual" incidence theory. Yi theoretical system of medicine broadly speaking, there is the main Toxin Factor Theory [60] in which: "toxin" is an important cause of $\mathrm{Yi}$ medical theory, $\mathrm{Yi}$ has become an important basis for the theory of the etiology and pathogenesis of medical discourse.

Yi medicine is based on that: "all diseases were born from poison". Poisonous pathogenic disease has two ways: both inside and outside. Other foreign drugs such as Immunotoxin, can produce a variety of infectious diseases prevalent toxin causes, worm snake beast trauma poison, and trauma. The philosophical concept of $\mathrm{Yi}$ medicine is based on the idea "set a thief to catch a thief, cure poison with poison". While the modern Yi medical evil effect is proposed on the basis of the theory of "evil poison", it started also that "evil cloud" is "evil poison", emphasis on dispel pathogenic toxin in the curing process [60]. Poison is coms from the onset of evil ways such as a variety of parasites toxin factor, trauma toxin factor (sword, fell wounded, and others). Based on this theory, poison cause changes in the human body and leads to diseases disease as a results of exposure to 
aetological agents such as insect beasts injury, poisoning, and trauma [61]. Toxin treatment principle: in the Yi poison evil etiological treatment is carried out by detoxification, righting centralizer detoxification, and other approaches of the three principles theory.

\subsection{Overview of the Yi Pharmacy Detoxification}

\subsubsection{Research of Yi Detoxification Drug [69]}

Yi medicine for poison concept based on that: Yi medical knowledge of drug toxicity is in the long-term life and health. $\mathrm{Yi}$ ancestors have since long time recognized that herbal drugs such as Aconitum and wrote book documenting the magic of special poisons and detoxification [71]. Animal toxicity refers to the venom of poisonous animals such as insect poison and venom; toxic plants includes germs, aconitum and others; mineral toxicity refers to toxic minerals such as mercury, realgar and other toxic materials and elements. Yi medicine "poison" refers to the meaning of contain toxic substances, is harmful to human body, or is access to a certain amount of intake or improper use, is easy to cause toxic effects of drugs, not referring to all of the $\mathrm{Yi}$ folk medicine or refers to the biased of $\mathrm{Yi}$ ethnic medicine. The strength of the toxicity of Yi ethnic medicine generally can be divided into 4 classes: nontoxic, low poison, toxic, high poison level. Yi medicine poisoning refers to a certain amount or excess intake of toxic substances, resulting in the body and organ tissue damage. Yi Medical toxin poisoning belong in one treatment factors. Yi medical detoxification methods include three kinds of detoxification methods According to $\mathrm{Yi}$ concept, detoxification method refers to the treatment of symptoms from the body through getting rid of the use of the poison. Yi three medical detoxification methods refer to the elimination of toxin out of human body from the mouth, discharge from the stool, or from the skin glands discharge method. The use of three methods for toxin cause removal or discharge of poison effect and relieves symptoms caused due to the toxin. Whether or organs outside the top five Yun raw toxin, by symptomatic treatment, prompting toxin discharged, need to go through a certain discharge channel, and up and down two way is the body's detoxification channels.

\subsubsection{Single Herb Drug Detoxification Research [69-72]}

Yi medical understanding of "poison" has a poison inside and outside. Always removing toxin in the body or outside the poisonous drugs is collectively known as antidote. Single herb antidote summarized as follows: Glutinous rice are used as herbs in folk, Yi medical is used to be canker, mastitis with multi-topical external. Well praise even function is as detoxification, used in Chinese medicine poison, drug poisoning, can treat various sore whether inside or outside. Wo Pu reported on detoxification, attending to be snake bites and sores treatment. A Wu Ga, detoxification attending carbuncle [73]. The concept of utilization characteristics of $\mathrm{Yi}$ medical antidotes includes: First fire with fire, referring to use partial toxicity of these drugs to detoxify; Second, detoxification first, referring to $\mathrm{Yi}$ medical detoxification method of choice; Third, referring to the $\mathrm{Yi}$ medical detoxification internal and external treatment; Fourth, combine food and medicine, refers to be the use of $\mathrm{Yi}$ medical antidotes and some food and clothes in the treatment of some chronic toxicity.

\section{MIAO MEICINE DETOXIFICATION METHOD RESEARCH}

\subsection{Miao Medicine Detoxification [74]}

Many well-known methods for medication and treatment in Miao medicine are in form of a variety of quotidian made in the fight against the gas, such as drugs known as Miao medicine acupuncture, which work to reduce toxic ingredients.

\subsection{Miao Medicine Associated with Toxin Based Theory [74]}

Cult poison damage, usually caused by external factors seedlings medical disorders collectively referred to as cult poison, poison wind, thermal and other drugs. Miao doctors think that there is a root cause of poison produced by a variety of diseases, it is "toxic to the source of sickness" [75]. Toxin eliminating methods is are abundant, in Miao medicine and include: catch drug law, disinfection method, sepsis law, detoxification method, attack drug law, pull out poison method, G drug law, and others known as as the "detoxified nine method "[76]. The detoxification method is naturally become the one of the most important ways to treat the disease, according to Miao medical therapy.

\subsection{Research on Miao Detoxification Drug}

Miao medicine was under the guidance of medical theory; the Miao people always used natural medicine for the prevention and treatment of the disease [77]. Detoxification method is basically considered as the use of drugs or medication to resolve food poisoning. Miao medical practice reported many detoxification recipes. now drug detoxification prescriptions are summarized as follows: Ginkgo poisoning can be 
treated with white nutshell $30 \sim 60 \mathrm{~g}$ or Licorice $15 \sim$ $30 \mathrm{~g}$ [74]. Aconitum and snow artemisia poisoning can be treated with licorice, honey, green beans, honey suckle, and lotus. Nan xing or Rhizoma pinelliae poisoning can be detoxified by ginger and licorice. The sweet vine Paederia scandens which known as "nest a quack" in Miao medicine can be applied in detoxification and relieving pain [78]. Either single drug or combinations of more than one drug were applied in Mia medicine for detoxification purpose by ancient folk.

\section{STUDY RERESCH ON JINUOZU DETOXIFICA- TION METHODS}

The Jinuo is one of the least populous minorities in China. In Jinuo mountain they are often in the mysterious religious activities with herbal remedies. The Jinuo people in the long struggle with the many diseases and thus; they gradually accumulated rich experience with the application of detoxification drug.

The Jinuo antidote for detoxification was applied in many cases as follows: (1) A 100 to $200 \mathrm{~g}$ of fresh tree onions solution prepared using boiled water was used in the treatment of dimethoate poisoning. (2) Boiled water preparation of $200 \mathrm{~g}$ of Mao persimmon fresh leaves could be applied for the treatment of Jie flower poisoning. (3) The juice of fresh Centella asiatica was used in detoxification of mushroom poisoning [79, 80]. The same plant extract was also successfully used in the treatment of sulfur and phosphorus poisoning [81]. (4) Wild Peon leaf and root extract was used for the treatment of food poisoning, and applied as medicine for heat relief and detoxification [82]. Herbs belong to Melastomataceae family showed regulatory role in the treatment of immunocompromised mice and also exhibited antibacterial and antiviral activities [83]. (5) Modern research has found that guava leaves extract enhance the MA-104 cells against rotavirus infection [84]. Volatile oil extracted from guava leaves, Terrace mesothelin and ursolic acid ingredients, prove that they are able to reduce the virulence of rotavirus, and thus achieve the exhibit highly effective virus activity [85]. (6) The wood duck feet with bark smashed water decoction was applied as antidote for graceful jessamine herb poisoning [86]. (7) Radish with fresh leaf juice taken internally was also successfully used in the treatment of poisoning. (8) Lalang grass rhizome solution in form of imperata fresh root $(1000 \mathrm{~g})$, sugar $(500 \mathrm{~g})$ in water decoction, exhibited in vitro antibacterial and antiviral activity and showed significant inhibition of Shigella sonnei and Bacillus growth [87]. (9) White Rattan was also applied as antidote in the treatment of ulcers swollen Poison with 30g. (10) White Rattan: Jinuo language is called Niyouya, it is with fresh goods by daolan depositing and applies to mash outsourcing ulcers swollen poison. (11) Wild green valley: the Jinuo language is referred to as Lesheng, it is with fresh products. Its Whole herb remedies sore ulcers and unknown swollen poison by ectocyst.

\section{OUTLOOK AND CONCLUSION}

In summary, Chinese folk Medicine is huge treasure source of medications with diversified approaches. It should be studied in more depth, made full use of the theory and method of detoxification of Chinese folk medicine. This will help as guidance for the development of better modern detoxification drug. In addition, it will be helpful for the development of better detoxification approaches in clinical practices. Ethnic medicine, good antidote selection, and detoxification technology, in the field of Chinese Traditional Medicines need more exploration and research. Ethnic medicine with modern good antidote cross-integration, with solving detoxification poisoning problems associated to modern drugs will be indeed a new good approach. Throughout Chinese minority medicine, it does not have a lot of advanced medical science methods. However, in the face of all kinds of poisoning cases, the ancient people try to use drug detoxification and gradually form a set of detoxification medicine theory. The ancient folk medicine exploration steps have never stopped. We need to learn more from the writings of the ancient classical medical theories, and to integrate this knowledge in our current medical services. Since there are many ethnic medicines previously prescribed with good detoxification activities, these is a need to learn from the study of modern western medicine detoxification methods and techniques, in order to develop better national detoxifying drugs. Chinese minority medicine is a great treasure, especially as described in part in this work. Using, the eight ethnic-related medical detoxification medicine theory presented we can learn to develop many subsequent application. As for now the information available shows that China have 35 ethnic groups, of which there are 18 ethnic groups have weight ranging from medicine monographs, varying levels of clinical activity and relatively rich medicinal resources. However, it is interesting to know whether traditional medicine of ethnic minorities have their own independent medical theory system, especially with detoxification-related medical theory, more research are required to to explore this issue in depth. 


\section{ACKNOWLEDGEMENTS}

The work was supported by12th Five-year Key Construction Discipline of State Administration of Traditional Chinese Medicine "Dai Pharmacy"; Key Construction Discipline of State Administration of Traditional Chinese Medicine "Dai Medicine"; Folk medicine literature arrangement and $r \& d$ project of national medicine hospital preparations of the health department of Yunnan province (KY14); Students' Innovative Entrepreneurial Training Program of Yunnan University of Traditional Chinese Medicine. We thank Associate Prof. Ms. Yu Zupu for the helpful discussions and abstract. We are in debt to Prof. Ms. Li Xiufang for the help on Pharmacology of Traditional Chinese Medicine.

\section{REFERENCES}

[1] Cui J, Tang L. Introduction to Chinese Minority Traditional Medicine, University of Central Nationalities Publishers, Beijing, China 2007; p. 436.

[2] Zhen Y, Cai JF. A summary on Tibetan medicine. Tibetan Studies 2002; 2: 79-85 http://dx.doi.org/10.3969/j.issn.1000-0003.2002.02.011

[3] Wang CY. The introduction to the basic theory of Tibetan medicine. J of Northwest Univ For Nationalities (Philosophy and Social Science) 1980; 2: 63-75.

[4] Ge SCL. Preliminary study of Tibetan medicine three cause. Tibetan Studies 1993; 4: 69-74.

[5] Xia YY, Lu M. Relationship between Tibetan and Chinese medicine and its characteristics. J of Med \& Pharm of Chin Minor 2000; S1: 106-8.

[6] Ding LH, Li ZP. Overview on the basic theory of Tibetan medicine. $\mathrm{J}$ of Med \& Pharm of Chin Minor 1996; 4: 3-4.

[7] Duo J. Overview on Tibetan medicine Five source theory. J of Med \& Pharm of Chin Minor 1998; 1: 3-4.

[8] Yang CS. Probe into the theory of Tibetan medicine and It's modem study. Chin J of Ethnomed and Ethnopharm 2001; 2: 63-5.

http://dx.doi.org/10.3969/.issn.1007-8517.2001.02.001

[9] Li LY, Zhan D, Wei YF, et al. Conservation of endangered species resources of Tibetan medicine in China. Chin $\mathrm{J}$ of Chin Materia Medica 2002; 8: 4-7. http://dx.doi.org/10.3321/j.issn:1001-5302.2002.08.001

[10] Yang CM, Hou SX, Li CY. The present situation and reflections on modernization of Tibetan medicine. Chin $\mathrm{J}$ of Chin Materia Medica 2001; 2: 8-10. http://dx.doi.org/10.3321/i.issn:1001-5302.2001.02.002

[11] Huang QP, Pan HM. Pharmacological effects and clinical application of pearls. Lishizhen Med and Materia Medica Resea 2000; 6: 564-5. http://dx.doi.org/10.3969/j.issn.1008-0805.2000.06.093

[12] Li MCR, LiuJQ, Hu WX.The advance research on Tibetan medicines. Northwest Pharm J 2007;6:350-1. http://dx.doi.org/10.3969/j.issn.1004-2407.2007.06.038

[13] Xiao PG, Xia GC. Compilation of Tibetan medicine commonly used drugs. J New Trad Chin Med 1973; 7: 39-41.

[14] Xiao PG, Xia GC. Compilation of Tibetan medicine commonly used drugs (continued). J New Trad Chin Med 1973; 7: 37-41.
[15] Zhang JM, Fu SW, Zhao J, et al. Research progress of chemical constituents, pharmacological activities and quality control of Tibetan medicine Pyrethrum tatsienense. Chin $\mathrm{J}$ of Pharm Analy 2012; 11: 2089-93. http://epub.cnki.net/kns/ brief/default_result.aspx

[16] Guan F, Wang YH. Pharmacological Progresses and Clinical Applications of Traditional Tibetan Herb Lamiophlomis Rotate. World Scien and Techno - modernization of Trad Chin Med and Materia Medica 2007; 2: 104-6. http://dx.doi.org/10.3969/j.issn.1674-3849.2007.02.019

[17] Zhang CJ. Evaluation of the antibacterial and antiviral activity of Tibetan medicinal and Investigation of molecular mechanism against HSV-2. PhD thesis, Lanzhou Univ,Gansu,China 2007, pp. 1-100. http://d.wanfangdata. com.cn/Thesis Y1213831.aspx

[18] Tai B. Overview on Mongolian history of pharmacy. J of New Chin Med 1977; 5: 56-58.

[19] Dong HY, Gao XM, Wang C, et al. Comparative researches on medicinal property theories of traditional Chinese medicine and traditional mongolian medicinal herbs. Chin $\mathrm{J}$ of Chin Materia Medica 2008; 5: 606-8.

http://dx.doi.org/10.3321/j.issn:1001-5302.2008.05.035

[20] Bao GL, Zhao ZH, Hai YM. Sketch of the Characteristic of drug administration in Traditional Mongolian medicine. $\mathrm{J}$ of North Pharm 2006; 3: 21-4. http://d.wanfangdata.com.cn/ Periodical_bfyx200602011.aspx

[21] Song L. Overview on Mongolian materia medica. J of Med \& Pharm of Chin Minor 2007; 13: 38-40. http://dx.doi.org/10.3969/j.issn.1006-6810.2007.01.019

[22] Bao JX, Bao L. The theory of holism Mongolian medicine in clinical. Chinese $\mathrm{J}$ of Ethnomed and Ethnopharm 1997; 4: 57.

[23] Gu WZ. The theory and characteristics of Mongolian Medicine. Chin Pharm J 1985; 1: 31-4.

[24] Ming ZE, Liu ZG. Brief discussion on Mongolian studies. Chin $J$ of Ethnomed and Ethnopharm 1994; 6: 43-4.

[25] Wu HJ, Yang YM. Current status of study in Traditional Mongolian pharmacology. $\mathrm{J}$ of Med \& Pharm of Chin Minor 2012; 18: 45-8.

http://dx.doi.org/10.3969/j.issn.1006-6810.2012.10.024

[26] Lan HJ. The study of chemical composition and antioxidation activity of four kinds Mongolian medicine. Master Thesis, Liaoning Normal Univ, Liaoning, China 2008, pp. 1-73. http://dx.doi.org/10.3866/PKU.WHXB201112303

[27] Tang LL. A preliminary study on the theory of law of Dai medicine "Ya Jie ". Master Thesis, Yunnan Univ of Trad Chin Med, Yunnan, China 2012, pp. 1-103. http://dx.doi.org/10.7666/d.y2109615

[28] Chen P.Zheng J, Zhang C, et al. The Researching Progress on the Basic Theory of Traditional Dai Medicine. J of Yunnan Univ of Trad Chin Med 2010; 1: 30-4. http://dx.doi.org/10.3969/j.issn.1000-2723.2010.01.010

[29] Fang J, Xu JX. Development and application of Dai ethnic medicine "Jajie". Chin J of Chin Materia Medica 2012; 14 2190-2.

http://dx.doi.org/10.4268/cjcmm20121434

[30] Peng CZ, Duan LS, Li XL. Collective toxicide drug frome traditional Dai medicine. $\mathrm{J}$ of Med \& Pharm of Chin Minorities 2005; $2: 16$

http://dx.doi.org/10.3969/j.issn.1006-6810.2005.02.016

[31] Xu XY, Yang M, Zhang XL, et al. Review on the research of Dai "antidote". J of Med \& Pharm of Chin Minorities 2007; 3: 73-5. http://dx.doi.org/10.3969/j.issn.1006-6810.2007.03.041

[32] Yu BH, Lin YF. Dai medicine Ya Jie (antidote) theory in clinical application. $\mathrm{J}$ of Med \& Pharm of Chin Minorities 2009; 10: 27-9.

http://dx.doi.org/10.3969/j.issn.1006-6810.2009.10.015 
[33] $\mathrm{Yu}$ BH. Talking about the features of Dai medical antidote. Yunnan J of Trad Chin Med and Materia Medica 2001; 1: 28. http://dx.doi.org/10.3969/j.issn.1007-2349.2001.01.033

[34] Lin YF, Yi Z, Yan HD, et al. On the features of Dai medicine Ya Jie(antidote). Yunnan J of Trad Chin Med and Materia Medica 2002; 3: 38-40. http://dx.doi.org/10.3969/j.issn.1007-2349.2002.03.041

[35] Ceng J, Ceng XR. Research survey of Dai medicine Ya Jie Sha $\mathrm{Ba}$ (one hundred Capsule). Chin $\mathrm{J}$ of Ethnomed and Ethnopharm 2009; 21: 23-4.

http://dx.doi.org/10.3969/j.issn.1007-8517.2009.21.014

[36] Peng $\mathrm{X}$, Zhao $\mathrm{YH}$, Liao $\mathrm{RL}$, et al. Study on qualitative criterion of Daizu medical Yajie tablets. J of Med \& Pharm of Chin Minorities 2001; 4: 28.

http://dx.doi.org/10.3969/j.issn.1006-6810.2001.04.022

[37] Zhang C. Dai medicine basic theory, Chinese medicine press, Beijing, China 2007 ; pp. 1-56.

[38] Wang XM, Zhang JS, Gao YT. Study on the Antioxidant Activities of Arundina Graminifolia Dai Medicines. J of Yunnan Nationalities Univ(Natural Sciences Edition) 2009; 2: 148-50. http://dx.doi.org/10.3969/.issn.1672-8513.2009.02.016

[39] Dai R, Li XR, Li SM, et al. Effect of Yajieshaba on the dysequilibrium alcoholism mice. $J$ of Yunnan Univ of Trad Chin Med 2012; 35: 8-10.

http://dx.doi.org/10.3969/j.issn.1000-2723.2012.02.003

[40] Duan $\mathrm{XH}$, Zheng J, Wang $\mathrm{H}$, et al. Research on the toxicity of antidote compounds of Dai medicine $\mathrm{Ya}$ Jie Sha Ba. Yunnan J of Trad Chin Med and Materia Medica 2013;34: 56-8. http://d.wanfangdata.com.cn/Periodical_ynzyzyzz 201310033.aspx

[41] Zhang T, Ye JZ, Tang HR, et al. The Anti-allergic reaction of'Yajieshaba'-one of the Dai antidote. J of Yunnan Univ of Trad Chin Med 2012; 35: 5-7.

http://dx.doi.org/10.3969/j.issn.1000-2723.2012.02.002

[42] Li XR, Dai $\mathrm{R}$, Wang $\mathrm{H}$, et al. Experimental study on alcoholism relieving Eefect of Yajieshaba. $\mathrm{J}$ of Med \& Pharm of Chin Minorities 2012; 18: 60-3. http://dx.doi.org/10.3969/j.issn.1006-6810.2012.11.027

[43] Gao M, Wang SG, Ni K, et al. Protective effect of Dai baijie on liver injury induced by AIDS antivirals. Yunnan $\mathrm{J}$ of Trad Chin Med and Materia Medica 2014; 35: 60-1. http://d.wanfangdata.com.cn/Periodical_ynzyzyzz201404035. aspx

[44] Zhang RL. Wang T, Xu YF, et al. The Present situation and prospects of Traditional Dai medicine in Xishuangbannan Dai autonomous prefecture. Chin $\mathrm{J}$ of Ethnomed and Ethnopharm 2014; 6: 7-9.

[45] Liang QC. Development situation and prospects of Guangxi Zhuang medicine. J of Med \& Pharm of Chin Minor 2007; 13: 68-70.

http://dx.doi.org/10.3969/j.issn.1006-6810.2007.07.038

[46] Dai B, Qiu CC. The review, present condition and way of thinking of Zhuang nationality medicine development in Guangxi province. Chin $\mathrm{J}$ of Ethnomed and Ethnopharm 2007; 1: 1-6.

http://dx.doi.org/10.3969/j.issn.1007-8517.2007.01.001

[47] Li Q. Study on the history of Zhuang Medicine. Anthology of Med 2002; 21: 80-1.

http://dx.doi.org/10.3969/j.issn.1673-6575.2002.01.066

[48] Pang YZ, Huang DL, Jiang ZL. On the basis of practice and its influencing factors theory of the formation of Zhuang medicine. Guangxi J of Trad Chin Med 2009; 32: 22-4. http://dx.doi.org/10.3969/j.issn.1003-0719.2009.01.012

[49] Huang HR. Zhuang medicine finishing excavation. Guangxi J of Trad Chin Med 2001; 24:1-2. http://dx.doi.org/10.3969/j.issn.1003-0719.2001.03.001
[50] Pang YZ, Zeng SW. Zhuang medicine history, current situation and problems. $\mathrm{J}$ of Med \& Pharm of Chin Minorities 2008; 14: 1-3. http://dx.doi.org/10.3969/j.issn.1006-6810.2008.08.001

[51] Huang JX. Construction and expansion of Zhuang Theoretical System. J of Guangxi Univ for Nationalities(Philosophy and Social Sciences Edition) 2012; 2: 27-33.

[52] Huang Y. The Investigation of the Chemical Constituents on Hypericum Japonicum Thunb. Master Thesis, Guangxi Univ, Guangxi, China 2006; pp. 1-99. http://dx.doi.org/10.7666/d.y985522

[53] Teng HL. Formation and development of Zhuang drugs. Chin $\mathrm{J}$ of Ethnomed and Ethnopharm 2008; 17: 5-6. http://dx.doi.org/10.3969/j.issn.1007-8517.2008.03.003

[54] Jiang ZL, Pang YZ. Overview of Zhuang medicine cure prescription characteristics. Guangxi J of Trad Chin Med 2007; 30: 31-2. http://dx.doi.org/10.3969/j.issn.1003-0719.2007.06.017

[55] Rong XX, Huang DL. History of Zhuang medicine stated. Acta Chin Med and Pharmaco 1993; 2: 2-4.

[56] Pang YZ. Discussion on the poison theory of Zhuang medicine. Lishizhen Med and Materia Medica Resea 2008; 19: 2810-1. http://dx.doi.org/10.3969/j.issn.1008-0805.2008.11.122

[57] Tang $\mathrm{HQ}$, Huang $\mathrm{CH}$, Huang XF, et al. Comparative analysis of "toxic" theory of Zhuang medicine theory and Traditional Chinese Medicine. Chin $\mathrm{J}$ of Trad Chin Med and Pharm 2013; 28: 902-4.

[58] Zhang CQ, Yu YS, Luo ZG, et al. Medical summary of Yao nationality in Guizhou province. Chin $\mathrm{J}$ of Ethnomed and Ethnopharm 2001; 5: 249-51.

http://dx.doi.org/10.3969/j.issn.1007-8517.2001.05.001

[59] Li T, Qin SJ. Practical Yao Medicine, Chinese Medical Science and Technology Press, Beijing, China 2004; p. 1520.

[60] Dai B, Li ZD, Qiu CC, et al. Investigation of "tiger cow drill wind" category of Yao traditional medicine. ChinJ of Ethnomed and Ethnopharm 1998; 2: 28-34.

[61] Liu YH, Ding F. Overview on Yao and Yao medicine. Hunan $\mathrm{J}$ of Trad Chin Med 1995; 5: 24-5.

[62] Mo LY, He ZW. The profit and loss balance theory of Yao medicine and clinical application. Chin $\mathrm{J}$ of Ethnomed and Ethnopharm 1996; 4: 7-8.

[63] Liu YP, Dong MJ, Huang $\mathrm{CH}$. Yaoyi in terms of "wind". J of Med \& Pharm of Chin Minorities 2009; 15: 4-5. http://dx.doi.org/10.3969/j.issn.1006-6810.2009.02.003

[64] Zhu RC, Liu YH. Investigation and study of Hunan Yao "wind medicine". Hunan J of Trad Chin Med 1995; 5: 26-8.

[65] Liu Y, Li XY, Mo HT. Overview of Yao drug "fierce tiger" pharmacological research and Clinical application. Inter Med of Chin 2008; 3: 607-9.

http://dx.doi.org/10.3969/j.issn.1673-7768.2008.04.067

[66] Pang SH, Yu SM, Huang LY. Research on Selecting 20 Traditional Anti-tumor Yao-folk Medicine in Guangxi. Guangxi $\mathrm{J}$ of Trad Chin Med 2006; 29: 53-7. http://dx.doi.org/10.3969/j. issn.1003-0719.2006.04.033

[67] Su MX, Fan ZY, Cen YZ, et al. A preliminary study on the anti viral activity of Yao medicine small purple cow. The fourth organic chemistry conference set Chinese Chemical Society (Vol. 1); 2005: Kunming Yunnan, provine: The fourth asian-australasian conference on organic chemistry, Chinese chemical society; 2005: p. 42

[68] Yang BL. The theory foundation of Chinese Yizu nationality medicine, Yunnan Nationalities Publishing House, Kunming, China 2004; p. 89-104.

[69] Yang BL. Chinese Yizu Pharmacy, Yunnan Nationalities Publishing House, Kunming, China 2004; pp. 1-656. 
[70] Yu Q, Yu FZ. Development history and applied study of Yi nationality medicine. Chin $\mathrm{J}$ of Ethnomed and Ethnopharm 2001; 1: 6-9.

http://dx.doi.org/10.3969/j.issn.1007-8517.2001.01.005

[71] Wu GF. Research on the development of Yizu medicine. J of Fujian Univ of Trad Chin Med 2010; 20: 62-3. http://dx.doi.org/10.3969/j.issn.1004-5627.2010.06.021

[72] Gu J, Liu Z. Study on present developing status of $\mathrm{Yi}$ nationality herbal medicine.Chin $\mathrm{J}$ of Ethnomed and Ethnopharm 2003; 5: 249-54.

http://dx.doi.org/10.3969/j.issn.1007-8517.2003.05.001

[73] Yan ZY, Liang JX, Chen X, et al. Varietal investigation and identification on herb of Yi nationality Dula. $J$ of Chengdu Univ of Trad Chin Med 2007; 30: 56-9. http://dx.doi.org/10.3969/j.issn.1004-0668.2007.02.022

[74] Lu KM, Wang FR. Miao medicine, Guizhou Science and Technology Press, Guiyang, China 2006; pp. 1-611.

[75] Du J, Liu XY, He K. Law says of seedling treatment poison methods. J of Med \& Pharm of Chin Minor 2007; 13: 25-6. http://dx.doi.org/10.3969/j.issn.1006-6810.2007.07.017

[76] Du J. Methods and feature of Miao medical therapy. Chin J of Trad Chin Med and Pharm 2007; 7: 483-5. http://dx.doi.org/10.3969/j.issn.1673-1727.2007.07.019

[77] Lu DW, Du J. A study of the theory of drug property and Shujing of Miao national herbs. J of Tongren Univ 2008; 10: 137-9.

http://dx.doi.org/10.3969/j.issn.1673-9639.2008.06.036

[78] Yang JX, LiuXM. Miao nationality medicinal food 3. J of Guiyang College of Trad Chin Med 1996; 4: 53-4.

[79] Peng ZZ. The Jinuo folk detoxification collection. J of Med \& Pharm of Chin Minor 2003; 9: 19.

http://dx.doi.org/10.3969/j.issn.1006-6810.2003.03.012
[80] Guo SR, Duan H, Li E, et al. Investigation of the Jinuo folk medicine. Chin J of Ethnomed and Ethnopharm 1995; 6: 2833.

[81] Pan YG. Centella asiatica juice rescue wrongly sulfur, phosphorus poisoning three cases. J of New Chin Med 1976; 6: 50.

[82] Liu H, Fu J. Study progress of common melastoma herb. Guiding J of Trad Chin Med and Pharm 2008; 14: 90-1. http://dx.doi.org/10.3969/j.issn.1672-951X.2008.12.048

[83] Liang CL, Zhou JY, Wu JB, et al. Anti-inflammatory and analgesic effects of melastoma candidum and its influence on the immune function in mice. Chin Pharmacist 2012; $15: 1547-50$. http://dx.doi.org/10.3969/j.issn.1008-049X.2012.11.009

[84] Li D, Cheng TY, Dong ZS. Research status on guava leaves medicinal. Chin $\mathrm{J}$ of Animal Husbandry and Veterinary Med2008; 2: 15-6.

http://dx.doi.org/10.3969/j.issn.1671-6027.2008.02.006

[85] Lei Q. Study on the extraction of guava active substance and its pharmacological action. Master Thesis, Shantou Unive, Fujian, China 2006; pp. 1-60. http://d.wanfangdata.com.cn/ Thesis_D532373.aspx

[86] Li XW, Jiang JP, Li J. Study on pharmacognosy of duck foot wood. J of Chin Medicinal Materials 2008; 31: 514-5. http://dx.doi.org/10.3321/j.issn:1001-4454.2008.04.016

[87] Jiao k, Chen PD, He YY, et al. Research overview of cogongrass rhizome. Jiangsu $\mathrm{J}$ of Trad Chin Med 2008; 40: 91-3.

http://dx.doi.org/10.3969/j.issn.1672-397X.2008.01.054

(c) 2014 Wang et al.; Licensee Lifescience Global.

This is an open access article licensed under the terms of the Creative Commons Attribution Non-Commercial License (http://creativecommons.org/licenses/by-nc/3.0/) which permits unrestricted, non-commercial use, distribution and reproduction in any medium, provided the work is properly cited. 